ECOLOGY AND SOCIETY

Home | Archives | About | Login | Submissions | Notify | Contact | Search

ES HOME > VOL. 3, NO. 2 > ART. 11

Copyright (C) 1999 by The Resilience Alliance-

The following is the established format for referencing this article:

Scheffer, M. 1999. Searching explanations of nature in the mirror world of math. Conservation Ecology 3(2): 11. [online] URL: http://www.consecol.org/vol3/iss2/art11/

A version of this article in which text, figures, tables, and appendices are separate files may be found by following this link.

Perspective, part of Special Feature on McDonnell Centennial Essays

\title{
Searching Explanations of Nature in the Mirror World of Math
}

\author{
Marten Scheffer
}

\section{Wageningen Agricultural University}

- Abstract

- Introduction

- Flipping Lakes

- The Trophic Cascade

- Chaos in Plankton Dynamics

- So, What Do Models Really Tell Us?

- Theory as a Bridge between Disciplines

- Responses to this Article

- Acknowledgments

- Literature Cited

\section{ABSTRACT}

Despite the huge scientific progress of the last century, the dynamics of complex systems such as the atmosphere, human societies, and ecosystems remain difficult to understand and predict. Nonetheless, our ability to carve the future depends largely on our insight into the functioning of such complex systems. Complex systems are the focus of considerable mathematical theory. Rather than referring to any particular part of the world, such theory addresses what seems to be another world: a world of strange attractors, catastrophe folds, torus destruction, and homoclinic bifurcations. So disparate is the language and notation in this discipline that it is hard to imagine that it has any thing to do with reality as we know it. Indeed, it deals with a kind of mirror world, but in fact, underlying structures of the real world show up in this mirror world with a beautiful clarity that can never be seen in reality. This essay is about the relationship between this world and reality. Examples are taken from the work on aquatic ecosystems, starting with a view on the scale of entire lakes that can have multiple stable states, then zooming in on food web interactions in the lake, and further down to reveal chaos in the algal community.

KEY WORDS: bifurcation, catastrophe, chaos, cycle, Daphnia, fish, macrophyte, model, multiple stable states, plankton, predation, trophic cascade.

Published: December 15, 1999

\section{INTRODUCTION}

As far back as we can trace, human beings have tried to explain and control their overwhelmingly complex and threatening environment with tales, beliefs, and rituals. Only relatively recent is the development of science, a systematic approach that is somehow different from anything we did before, and so successful in solving problems that many people have gained a deep faith in our ability to "carve the future." Not everyone, however, feels equally 
confident in this extrapolation of scientific victory. Most of the success comes from branches of science that study only tiny subsets of the complex world, and the disciplines that attempt to study larger chunks, such as ecology, sociology, and climatology, seem to make much less progress. Nonetheless, they deal with questions that really matter to us in the long run. The challenging complexity with which these disciplines struggle is also a major focus of dynamical systems theory. Rather than referring to any particular part of the world, this theory addresses what seems to be another world: a mathematical world of strange attractors, catastrophe folds, and metastable states where torus destruction and homoclinic bifurcations are everyday events. So disparate is the language and notation in this discipline that it is hard to imagine that it has anything to do with reality as we know it. Indeed, it deals with a kind of mirror world, yet underlying structures of the real world show up in this mirror world with a beautiful clarity that can never be seen in reality.

This essay is an attempt to transmit the fascination of both worlds, the joy of recognizing glimpses of one in the other, and the idea that one can learn about reality by studying that strange other world out there. I take the reader through a series of examples from my work on aquatic ecosystems, starting with a view of entire lakes that can shift in a catastrophic way from one state to the other, then zooming in on intricate food web interactions in the lake, and further to an even more detailed scale level to reveal chaos in the algal community. I close with a reflection on the fundamental problems and future possibilities of using mathematical models for explaining the behavior of complex systems.

\section{FLIPPING LAKES}

Few things are more fascinating to a child than looking through the crystal clear water of a lake or pond to an underwater world of small animals moving busily around among the gently waving forest of submerged plants. Unfortunately, if we tried to go back to the clear waters of our childhood, it is quite likely that the magnificent views of our memories would have vanished. Over the past decades, many shallow lakes and ponds in the vicinity of populated areas have changed into murky waters. The most common reason for such shifts is an overdose of plant nutrients (e.g., phosphorus) due to heavy use of fertilizers on surrounding land and an increased inflow of waste water from human settlements and industries. Nutrients stimulate the growth of microscopic algae that are suspended in the water, and blooms of this "phytoplankton" cause the well-known greenish turbid look of many lakes. Especially bothersome are blooms of so-called "blue-green algae," which can float up to form smelly scums that may be toxic to humans and sometimes may even kill cattle and dogs drinking from the lake.

Importantly, phytoplankton blooms also trigger a series of dramatic changes in the underwater world (Moss 1988, Jeppesen et al. 1998, Scheffer 1998). The algal turbidity prevents light from reaching the lake bottom, and in the resulting permanent darkness, the lush fields of submerged plants that are characteristic of clear, shallow water die off. With the loss of submerged vegetation comes the disappearance of the countless small animals that depend on weed beds for shelter and food. Many fish species, in turn, forage on such animals or need the plants in which to deposit their eggs or hide from larger predators. With the loss of these species, a monotonous community remains, dominated by fish that find their food in barren sediments. Perhaps most spectacular is the drop in the numbers of birds that visit the lake. Many shallow lakes are known to harbor thousands of migrating ducks, swans, and coots that come to forage and rest during fall migration. When such lakes become turbid and loose their vegetation, bird numbers typically drop by one or two orders of magnitude. The diversity of animal and plant communities of shallow lakes in the turbid state is strikingly lower than that of clear lakes (Fig. 1).

Fig. 1. Schematic representation of a shallow lake in a vegetation-dominated clear state (upper panel) and in a phytoplankton-dominated turbid state in which submerged vegetation is largely absent and fish and waves stir up the sediments (from Scheffer 1997). 

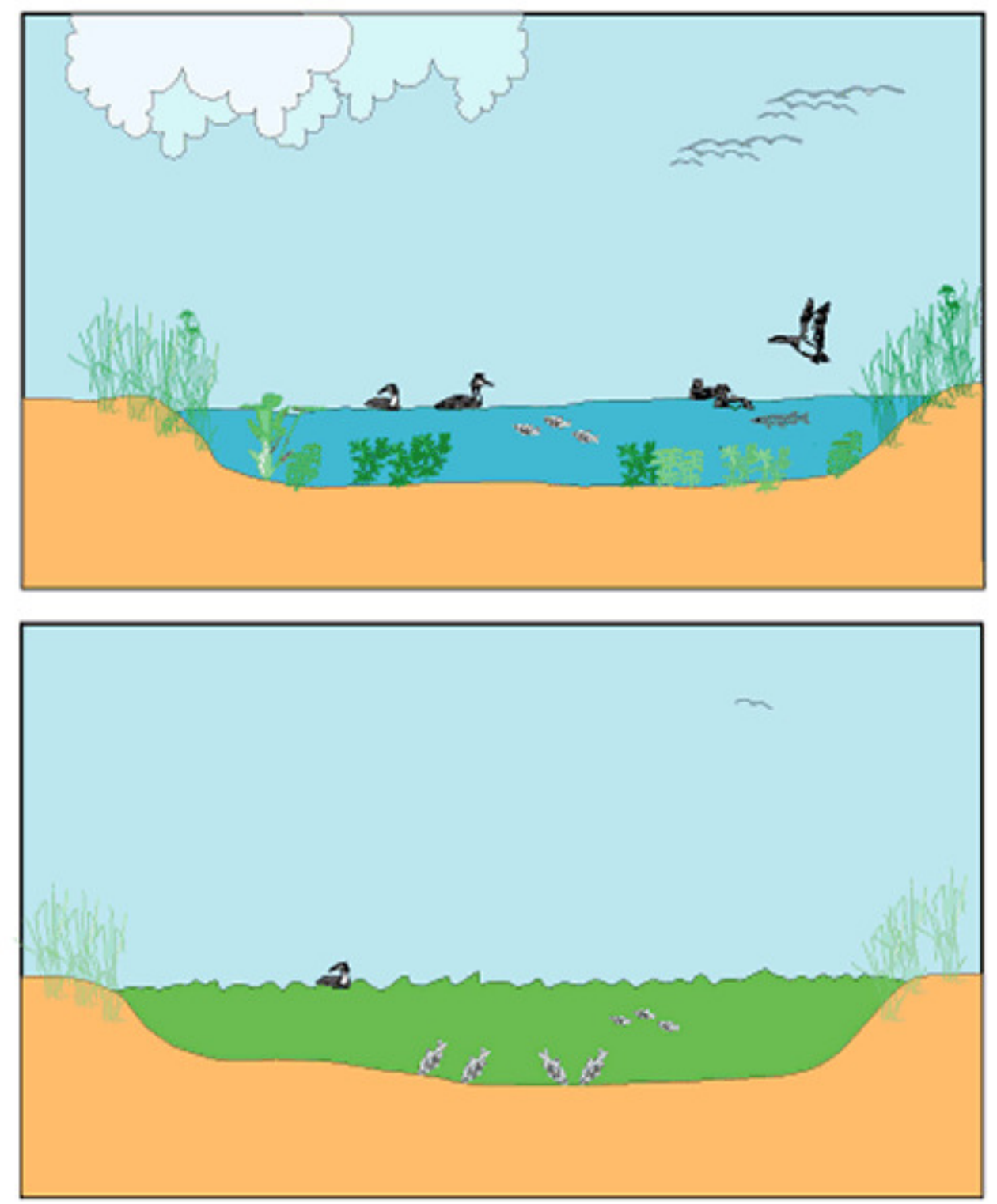

The devastating effect of overloading lakes with waste nutrients is called "eutrophication." It is generally recognized as a major problem, and many programs to reduce the nutrient level in lake water have been set up over the past decades. Large amounts of money are invested in wastewater purification plants, and farmers are often forced to reduce fertilizer use and invest in technology for recycling cattle dung. Although many lakes have recovered quite well in response to such eutrophication control programs, others have shown hardly any improvement, remaining unattractive, murky pools despite all investments. Shallow lakes are notoriously hard to restore. Even if the nutrient load is reduced to values well below those at which the collapse of the clear and vegetated state occurred, shallow lakes tend to remain in a highly turbid, eutrophic state.

Problems with restoring shallow lakes have required intensive efforts to tease apart the mechanisms that explain this disparate behavior. Although many factors appear to be involved, a positive feedback in the development of submerged vegetation is probably the main explanation. Apparently, submerged plants can reduce the turbidity of the surrounding water, thereby increasing underwater light levels and thus enhancing their own growth conditions. The way in which vegetation affects turbidity is not yet completely understood, but many different mechanisms are known to be involved. The most important ones are: (1) plants provide a refuge against fish for waterfleas (zooplankton), which, in turn, clear the water by grazing on phytoplankton (Timms and Moss 1984, Lauridsen and Lodge 1996, Jeppesen et al. 1998, Lauridsen et al. 1998); (2) weed beds prevent resuspension of sediment particles by wave action (James and Barko 1994, Barko and James 1998); (3) vegetation can suppress algal growth by reducing nutrient concentration in the water (Van Donk et al. 1993, Kufel and Ozimek 1994); and (4) plants can release so-called "allelopathic" substances that are toxic to algae (Kogan and Chinnova 1972, Gross et al. 1996, Gross 1999). 
Fig. 2 summarizes these mechanisms. A simple way of evaluating the effect of the depicted interactions is to multiply the signs along the path through the scheme. This exercise shows that, through all depicted routes, turbidity promotes turbidity and vegetation promotes vegetation. One can easily imagine that these positive feedbacks may give rise to two alternative stable states: a clear one in which plants clear up the water and thereby protect their own growing conditions, and a turbid state, which plants cannot colonize. At first sight, this seems like a convincing argument that lake ecosystems, in general, will have alternative equilibrium states. However, this would be a too easy jump to the conclusion. Observations suggest that the existence of alternative stable states in lakes should be limited to particular situations. First, the hypothesized stabilization of the vegetated state seems unlikely in deep lakes where plants are always limited to the relatively narrow shallow zone along the shores. Clearly this fringe of vegetation cannot have the dramatic impact on turbidity found in shallow lakes that can be entirely vegetated. Also, in shallow lakes, the existence of alternative stable states should be limited to an intermediate range of nutrient levels, as it is known that lakes that have very low nutrient contents are rarely turbid, and very high nutrient loading usually eliminates vegetation. Therefore, the demonstration of stabilizing mechanisms per se is not sufficient to conclude that a lake has alternative stable states.

Fig. 2. Feedbacks that may cause a vegetation-dominated state and a turbid state to be alternative equilibria. The qualitative effect of each route in the diagram can be computed by multiplying the signs along the way. This shows that both the vegetated and the turbid state are self-reinforcing (from Scheffer et al. 1993).

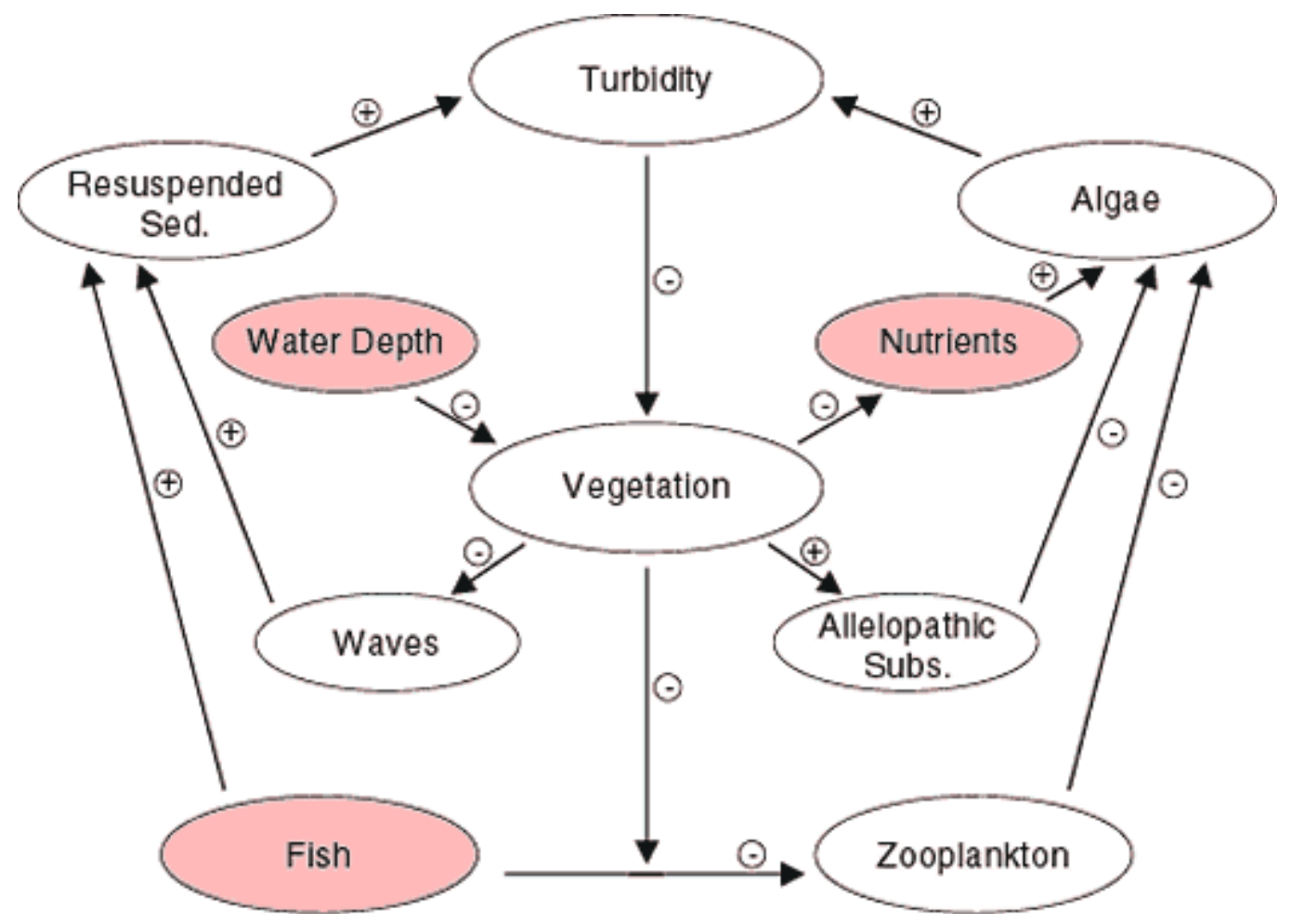

In order to understand how nutrient loading and lake depth may affect the ecosystem, we need to turn to models rather than qualitative reasoning. Although relatively complex mathematical models are needed to capture the dominant mechanisms that are involved, a very simple graphical approach suffices to illustrate the main point (Scheffer 1990, Scheffer et al. 1993). The graph is based on three assumptions: (1) turbidity increases with the nutrient level; (2) vegetation reduces turbidity; and (3) vegetation disappears when a critical turbidity is exceeded. In view of the first two assumptions, equilibrium turbidity can be drawn as two different functions of the nutrient level (Fig. 3): one for a plant-dominated situation and one with a systematically higher turbidity for an unvegetated situation. The third assumption translates into a horizontal line representing the critical turbidity for vegetation survival. Above this line, vegetation will be absent, in which case the upper equilibrium line is the relevant one; below this turbidity, the lower equilibrium curve applies. The emerging picture shows that, over a range of intermediate nutrient levels, two alternative equilibria exist: one with clear water and aquatic plants and a more turbid one without vegetation. At lower nutrient levels, however, only the macrophyte-dominated equilibrium exists, whereas at the highest nutrient levels there is only the turbid equilibrium without vegetation. If the lake is in a clear state (on the lower branch of the graph), an increase in nutrient level will lead to a gradual and moderate 
rise in turbidity until the critical turbidity for plant survival is reached (horizontal line). At this point, vegetation collapses and the lake "jumps" to the turbid upper branch. Reduction of nutrients after this catastrophic transition does not result in a return of plants until the critical turbidity is reached again. Note that this backward switch happens at a much lower nutrient level than the forward switch. Thus, reduction of the nutrient level to values at which the lake used to be clear and vegetated often will not lead to restoration of that state. This is precisely the frustrating experience of many lake managers. The explanation in a nutshell is that, in the absence of the clearing effect of vegetation, the water remains too turbid for vegetation to return.

Fig. 3. Alternative-equilibrium turbidities caused by disappearance of submerged vegetation when a critical turbidity is exceeded. The arrows indicate the direction of change when the system is not in one of the two alternative stable states (from Scheffer et al. 1993).

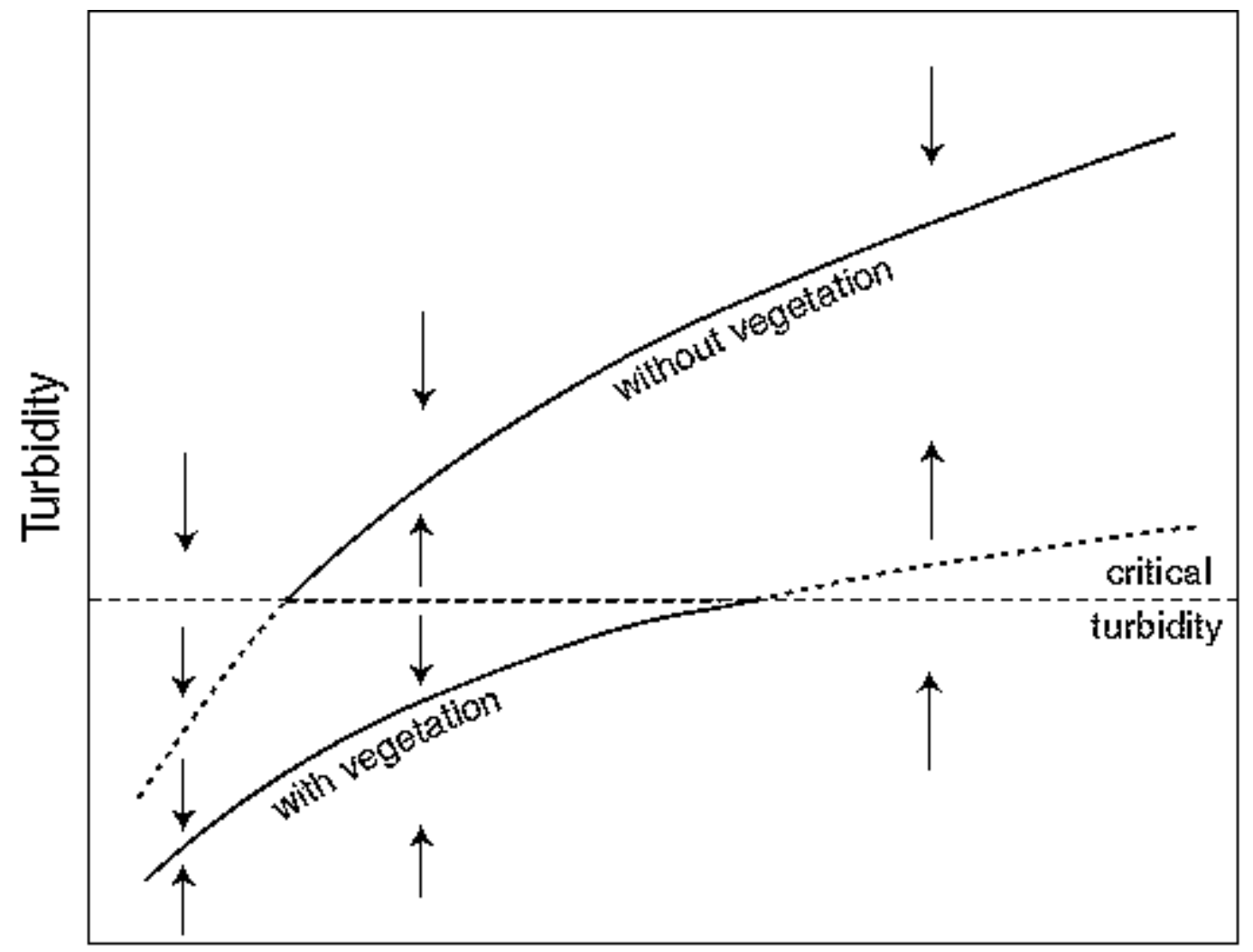

Nutrients

Clearly, this graphical model is a rather extreme simplification of the functioning of lake ecosystems. However, more elaborate mathematical models and analysis of the behavior of many lakes confirm the main result: shallow lakes may have alternative stable states over a certain range of nutrient levels. The implications of alternative stable states for lake management can be visualized in an intuitive way by means of so-called "stability landscapes" (Fig. 4). The bottom plane of this composed figure shows a line that indicates how turbidity increases with the nutrient level. The interpretation is analogous to that of the main sections of the previous graph (Fig. 3). The middle part of the "folded" line represents the critical turbidity for plant survival. The two outer sections represent the clear and the turbid state. At five different nutrient levels, a stability landscape is drawn to show the equilibria and their stability. The system, like a rolling ball, will be attracted to the valleys. These correspond to stable parts of the folded curve on the bottom plan, whereas the hilltops represent the threshold turbidity corresponding to the dashed middle section of the curve. Note that the front landscape represents a situation with heavy nutrient loading in which just one equilibrium exists, a turbid one, whereas the rear picture represents the pristine state of a lake, a low-nutrient situation in which a clear-water equilibrium is the only possible stable state. Between these two extremes, there is a range of nutrient levels over which two valleys, and hence two alternative stable states, exist.

Fig. 4. "Marble-in-a-cup" representation of the stability properties of lakes at five 


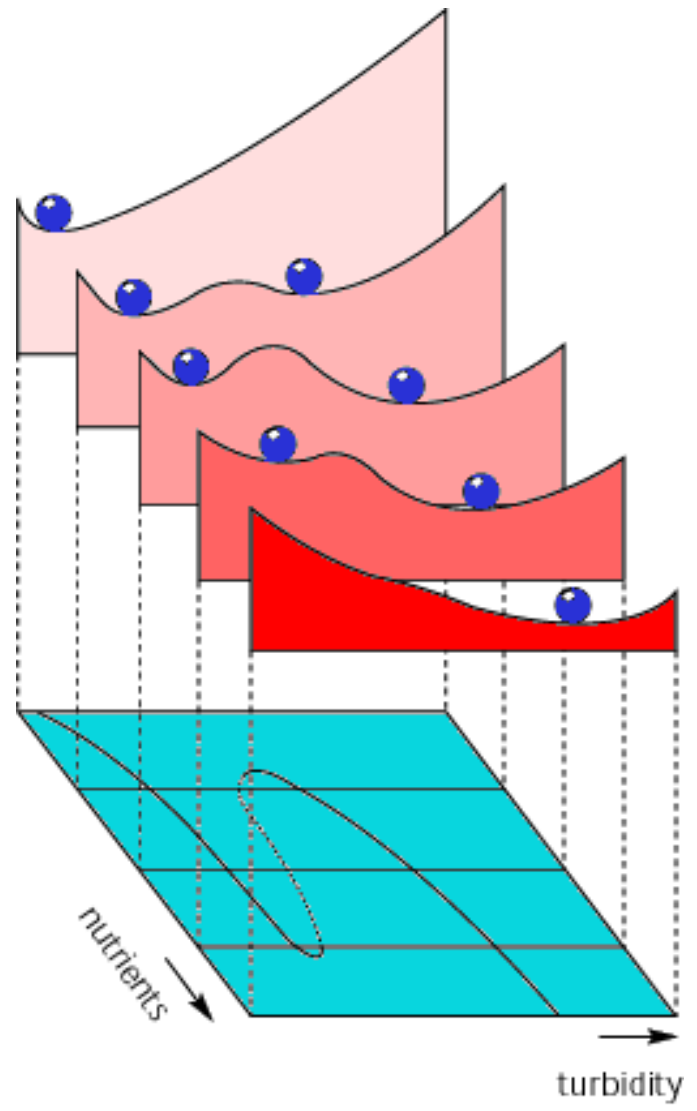

The response of a lake with such properties to eutrophication and subsequent restoration efforts can also be understood from this representation. Starting from the pristine state, a moderate increase in nutrient level gives rise to an alternative turbid valley, but if no large perturbations occur, the lake will stay in the clear state. Continuing enrichment, however, gradually causes the size of the clear valley to shrink to nil, making the lake more and more vulnerable to perturbations such as storms or plant kills that can bring the system across the hill to the attraction valley of the turbid state. However, even in the absence of perturbations, the period in which the lake stays relatively clear despite the nutrient loading will finally end with a catastrophic transition into a turbid state, as the valley around the clear water state disappears. Attempts to restore such lakes by reduction of the nutrient level may often have little effect, because the system will tend to stay in the turbid valley of attraction.

The good news is that, in this situation, a change to the alternative clear-water equilibrium can be achieved by "shock therapy." In terms of the stability landscapes, once the nutrient level has been reduced enough to allow the alternative clear valley to exist, one can force a switch to that alternative stable state by "pushing the ball over the hilltop." More specifically, such an intentional perturbation could be a temporary reduction in the lake turbidity, sufficient to allow recolonization by submerged vegetation. The latter can be achieved in a surprisingly effective way by drastically reducing the fish stock of the lake, so-called "bio-manipulation." In numerous small, shallow lakes that are treated this way, vegetation quickly recovers and the lakes remain in an apparently stable clear and vegetated state for many years (Moss 1987, Gulati et al. 1990, Jeppesen et al. 1990, Meijer et al. 1994).

Biomanipulation is relatively cheap, and the first spectacular results caused some over-optimism among lake managers: 'Why bother about expensive nutrient control if a winter of good fishing can cure the lake?" The theory, however, shows that no stable clear state exists if the nutrient level is too high. Trying to restore a lake that receives a heavy nutrient loading by mere fishing is like pushing the ball uphill in the front stability landscape. If you stop pushing, the ball will inevitably roll back to the turbid valley. Indeed, in most cases the shock therapy is likely to work only if the nutrient conditions have been improved first.

Although details of the mathematical models used in these analyses are not easily grasped by outsiders, the main result condensed in this stability graph (Fig. 4) has played a crucial role in transmitting the take-home message for lake managers and politicians: "a combination of nutrient control and fishing is far more cost-effective than investing in only one type of measure." 


\section{THE TROPHIC CASCADE}

The trick of removing fish to clear the water is a fascinating way of using ecological mechanisms to our advantage. In short, what happens is that reduction of the fish stock allows their favorite food, water fleas, to flourish and graze down phytoplankton to a low level. This effect of fish (through water fleas) on phytoplankton has been termed a cascading trophic interaction, as the impact cascades down the trophic levels in the food chain (Carpenter et al. 1985). Such top-down control is among the most important topics in ecology, from an applied point of view, and it has a long history of controversies.

A generic black-and-white version of this cascade of trophic control was worked out by Hairston, Smith, and Slobodkin (HSS) (Hairston et al. 1960). Their message was that, in the absence of consumers, plants would be abundant and the world would be green. Introduction of uncontrolled herbivores would lead to an expansion of their population until their food plants were almost gone, resulting in a desert-like brown world. Subsequent introduction of carnivores would, in turn, lead to their expansion until the herbivore numbers were strongly reduced, allowing the world to become green again (Fig. 5). Substituting phytoplankton, water fleas, and fish for the three levels, this hypothesis corresponds well to observations on the trophic cascade in lakes.

Fig. 5. Top-down control in food-chains of different lengths, as suggested by the HSS hypothesis, which states that top-down control of primary producers occurs only in food chains with an odd number of links.

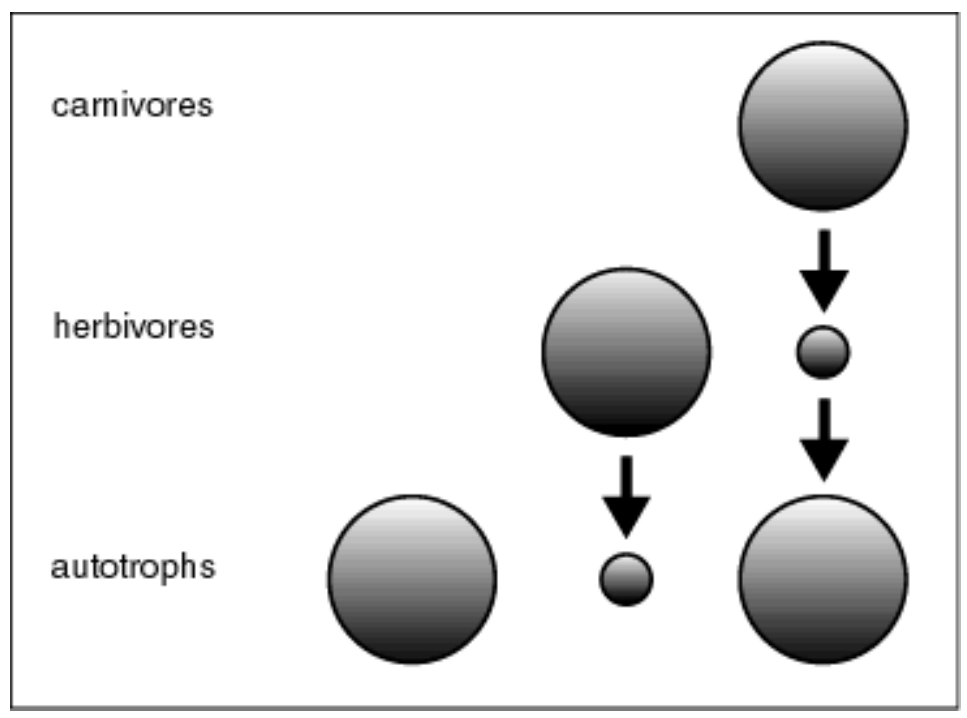

This HSS hypothesis and the trophic cascade theory have evoked strong debate, as many ecologists have felt that the potential for top-down control was greatly overestimated. The contrasting view is that the abundance of most organisms is determined by availability of food (or nutrients) rather than by predation. Interestingly, this controversy about the importance of top-down control was already a hot topic more than a century ago. A good impression of the situation is given in an early paper by the Italian scientist Lorenzo Camerano (Camerano 1880). His description of the scientific controversies in those days and the theory that he presents for explaining food chain dynamics contain such striking similarities with more recent developments in the field that it is worthwhile to look at his work. About the top-down bottom-up controversy, Camerano writes: "One of the most debated issues these days is that of animals which are useful and those harmful to crops ... . Naturalists are divided on this topic, as is well known, in two categories. ... Naturalists belonging to the first category" [those in favor of top-down control] "reason this way: the number of insects which cause damage to crops increases; that of birds, on the other hand, decreases. Now, birds feed to a great extent on insects, so if we increase the numbers of birds, the number of insects will decrease. The second category of naturalists" [those believing in bottom-up regulation] "think differently: the number of birds is high particularly in those places where insects are very abundant. When the number of insects decreases, so does the number of birds. Regions with low insect abundance also have few birds. The amount of insects in a region depends essentially on the amount of food found in it. ... Hence, they conclude: birds play only a small effect in destroying insects which may damage crops. Well-known naturalists have argued in favor of either one of the theories mentioned. However, the number of naturalists who support the first theory is decreasing every day, while those in favor of the second one increase." 
been obtained yet, for example, that applied science has been too sloppy ("an inclination to hasten to applications while disregarding data from pure science"). He proceeds to present a theoretical framework for understanding food chain dynamics that contains many of the key concepts of later ecological theory, for instance, the idea that consumer and food populations are in dynamic equilibrium: "It is a well accepted fact by all that animals and plants develop in direct proportion to the available food. From this it follows that no species, be it carnivore or herbivore, can develop beyond a certain limit which, if surpassed, would destroy the source of its own nourishment.

Equilibrium broken by the excessive growth of either kind of animal, would be again be reestablished. " Camerano explains in detail how the effect of disturbances on one trophic level will cascade through the food chain, the same idea that would provoke so much debate almost a century later.

Apparently, Camerano's reasoning was not appealing enough to the scientists of his day to create a school able to keep his ideas alive. Simple mathematical models of species interactions presented about half a century later by Alfred Lotka and by Vito Volterra were much more influential. Ever since their contribution, these and later, more realistic, minimal mathematical models have inspired scientists and have catalyzed the understanding of the dynamics resulting from species interactions. Indeed, the dynamical results of "eating and being eaten" are often rather intricate; in many cases, mathematical models have provided the little push needed to grasp the full implications of consumer-food interactions intuitively.

One of the fascinating aspects of such classical Lotka-Volterra models is their prediction that the interaction of populations of predators and their prey does not lead to an equilibrium state, but rather to a situation of eternal cycles. In biological terms, what happens over such a cycle is as follows. The predator population eats almost all of the prey. Because of the resulting food shortage, most predators die; this allows the remaining prey individuals to reproduce and grow freely in an environment with few competitors and few predators. The resulting wealth of food for the few surviving predators, however, allows their population to expand too; the recovered predator population consumes almost all of the prey, and the whole cycle starts from the beginning again.

Although such cycles are a favorite topic for theoretical analyses, predator-prey oscillations seem to be an exception, rather than the rule, in real nature. Luckily for aquatic ecologists, however, waterfleas seem to be such an interesting exception (McCauley and Murdoch 1987). Although these animals (Fig. 6) are no larger than 1-2 mm, they can become very abundant and filter the lake water in a highly efficient way, removing practically all of the planktonic algae. As a result, the waterflea populations collapse due to food shortage, the phytoplankton density recovers, and the few surviving waterfleas grow and reproduce to cause a new population peak that is doomed to collapse in the next cycle-phase. Such cycles can be produced from mathematical plankton models and also appear very nicely under controlled conditions in the laboratory. However, in the great outdoors, there are complications that make the patterns much more intricate. One complication is the presence of fish, predators that can completely wipe out waterflea populations. Another complication is the seasonal cycle in environmental conditions, slowing everything down in winter but triggering new growth and reproduction in spring.

Fig. 6. Waterfleas are small planktonic animals that filter the water to obtain their algal food. They can reach densities of hundreds of animals per liter and can reduce phytoplankton to low levels. However, waterfleas are also very vulnerable to fish predation, which explains their absence in many situations (from Scheffer 1997). 


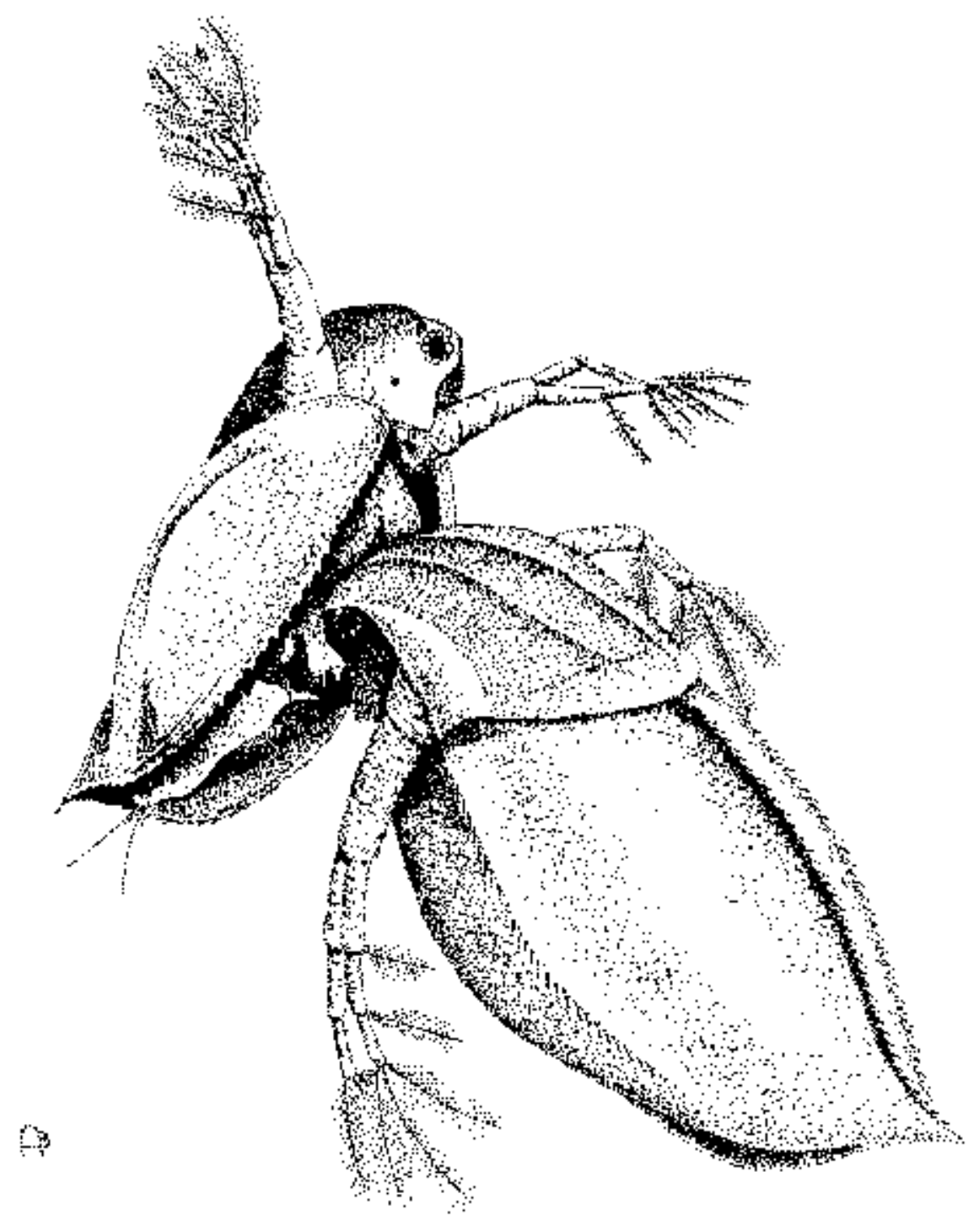

The effect of fish on waterfleas and other plankton is a major focus of current research in lake ecology. Experiments that explore how waterflea populations are affected by gradual change in fish predation pressure reveal a puzzling feature. Fish have little effect on waterflea density until a certain critical threshold is passed, at which time the waterflea population crashes completely and algal blooms can develop (Mills et al. 1987, McQueen and Post 1988). A closer look reveals that this sudden shift is, in fact, a catastrophic jump to an alternative stable state, just as in the case of the flipping lakes (Scheffer 1998). However, the mechanism is completely different. What happens in the fish-plankton case is that the fish (the consumer) overexploits its food (waterfleas). This is similar to what waterfleas do to the algae. The difference is that fish can survive on other food as well. Therefore, they do not necessarily die off after the collapse of waterfleas and, as a result, the overexploited state may be persistent rather than a transient phase.

A remarkably similar situation occurs on grasslands when cattle density becomes too high. The biologist Noy-Meir (Noy-Meir 1975) introduced an illuminating, simple graphical approach to analyze the risk of overgrazing in such systems. It is worth having a look at this approach, which is helpful not only for understanding the effect of cattle on grass, but also for explaining the effect of fish on zooplankton and many other overexploitation situations. The idea is to plot the production of the food population and the losses due to consumption in the same graph (Fig. 7). The difference between the two can then be interpreted as the net growth of the food population. 
Fig. 7. Graphical analysis of the stability of an exploited food population. At the intersections of the two curves, consumption equals production and the food population is in equilibrium. However, the equilibrium on the intersection marked by an open circle is unstable (From Scheffer 1997).

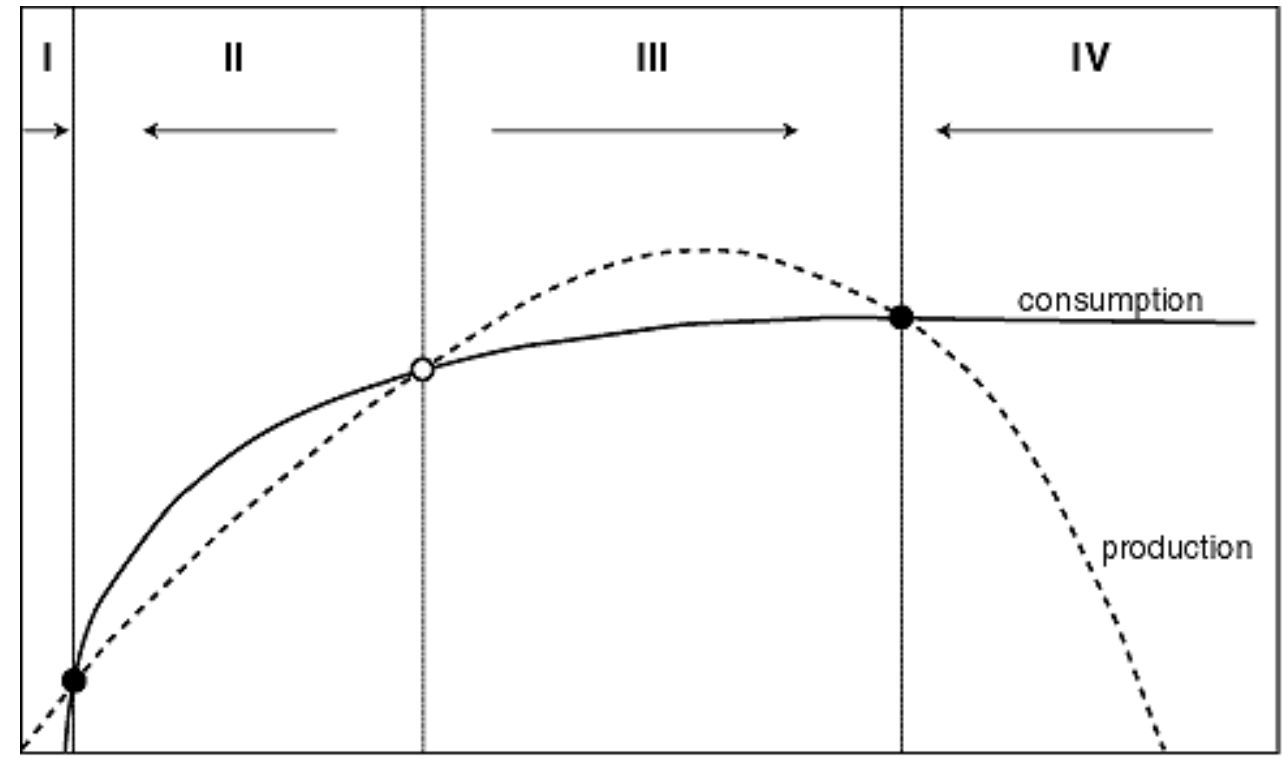

K

food biomass

The production of the food population plotted against its density shows an optimum. This is because prey individuals grow and reproduce well at low population densities, but there are just a few individuals, so overall productivity is still low. At the highest population densities, productivity is low because the carrying capacity of the environment is reached and severe competition prevents growth of the food population. The shape of the consumption curve can also be understood intuitively. Consumption drops to zero at low food density because the gathering of food by consumers becomes increasingly difficult. For high food densities, it saturates at the maximum consumption rate of the consumer individuals.

The curves can intersect in three points (Fig. 7). All three intersections are equilibria, as consumption balances growth. Obviously, the food population will increase if production is higher than the consumption losses (sections $I$ and $I I I$ ) and will decrease if consumption exceeds production (sections $I I$ and $I V$ ). This implies that the middle intersection point is an unstable equilibrium. If the system is in this state (like a ball on the top of a hill), the slightest disturbance will cause it to move to one of the stable states. This intersection represents the "breakpoint" food density below which the system collapses into an overexploited state with low food biomass, where production is very low.

Because overall consumption increases with the amount of consumers present, the saturation level of the consumption curve will increase in proportion to consumer density (Fig. 8). If one tracks the shift in equilibria with changing consumer density, it appears that the system responds in much the same way as flipping shallow lakes respond to nutrient loading. Starting from the lowest consumer density, there is just one equilibrium. With increasing consumer density, the equilibrium moves to the left. Food density decreases but productivity increases until the consumption curve becomes too high to intersect with the production curve. At that point, the equilibrium hits the unstable breakpoint and disappears. As a result, the system collapses into the overexploited state. If, after this collapse, consumer density is reduced in order to restore the productive state, the system shows hysteresis. It stays in the overexploited equilibrium with low food densities until the consumption curve has become low enough to let the intersections at the left side disappear. Again, this happens when the breakpoint collides with the stable state. Plotting the position of the three equilibria against consumer density (Fig. 9), one obtains a folded "catastrophe curve" that is analogous in interpretation to the ones obtained from the flipping lakes model (Figs. 3 and 4).

Fig. 8. Consumption increases with consumer density, and this affects the position of the 
stable and unstable equilibrium points at the intersections of the production and the consumption curves (see also Fig. 7). (From Scheffer 1997.)

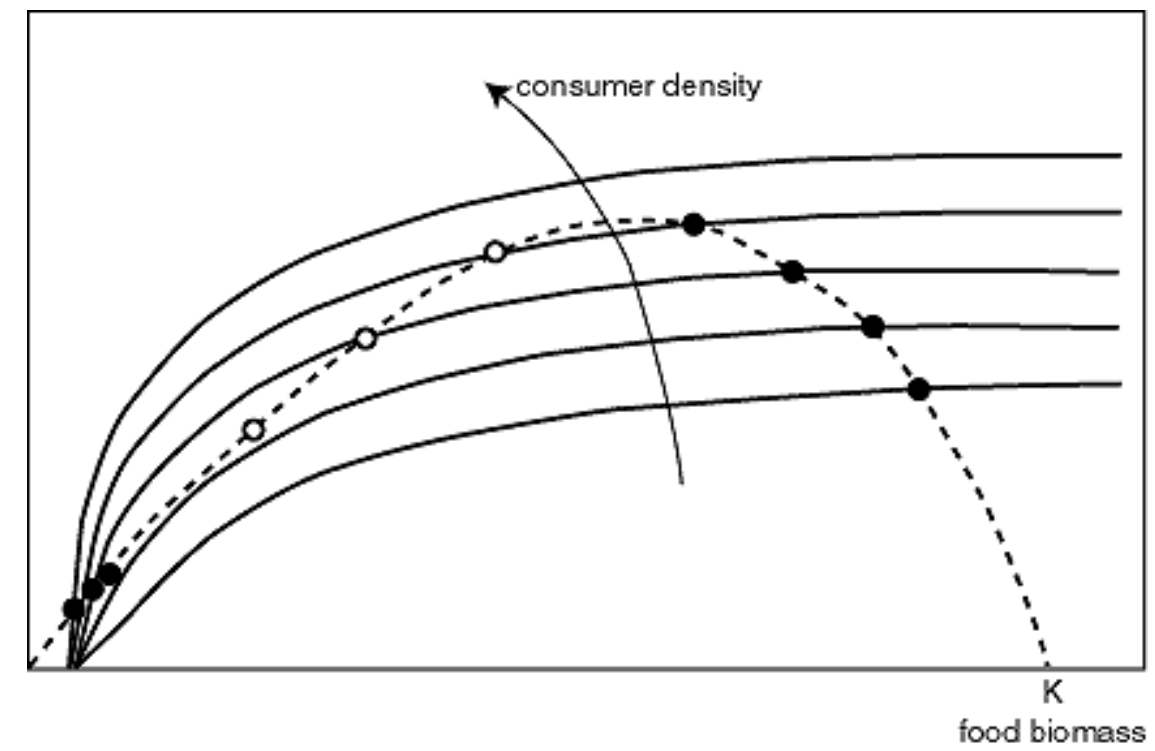

Fig. 9. Food density in equilibrium, plotted as a function of consumer density. The dashed middle section of the curve corresponds to the unstable breakpoints of the system (the open circles in Figs. 7 and 8). In the range of consumer densities over which this unstable equilibrium exists, the system tends to either of the two alternative stable equilibria, depending on the initial density of the food population relative to the breakpoint (from Scheffer 1997).

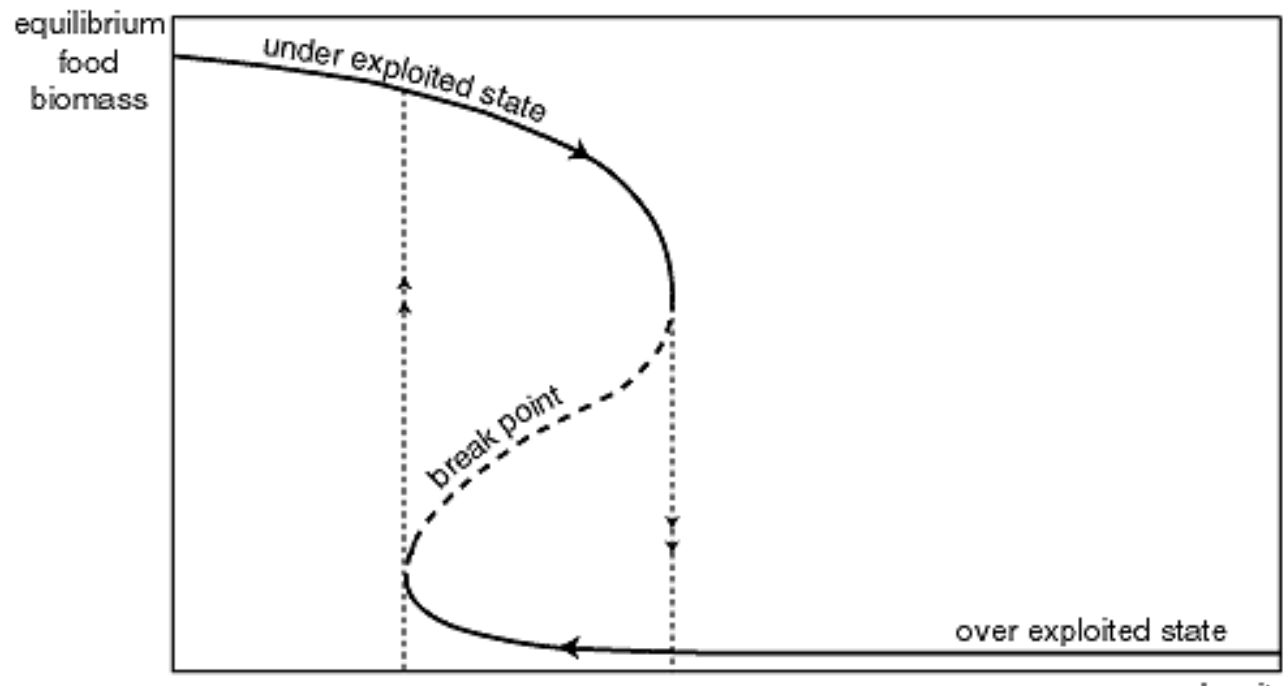

consumer density

Noy-Meir (1975) used this graphical model to explain the effect of overgrazing by cattle that is often observed in arid plant communities. There is, however, no reason why it should not apply to the effect of fish on waterfleas. Indeed, it fits well with the observation that waterflea populations collapse suddenly when a critical fish density is exceeded. However, the situation is really more complex in this case, because waterflea dynamics depend also on their interaction with phytoplankton, and, as argued, the waterflea-phytoplankton interaction generates cyclic oscillations. To understand better how the effect of fish cascades down to phytoplankton, we need to consider these dynamics of the planktonic system explicitly.

A discussion of the mathematical models that describe the fish-plankton interaction (Scheffer 1991a, Scheffer et al. 
1998b) would go beyond the scope of this essay, but the essence of the main results (Fig. 10) can be understood from a combination of the graphical models described in the previous sections. The sigmoidal line in the graph is analogous to the catastrophe fold in the Noy-Meir model (Fig. 9). In this case, it indicates that, with increasing fish (rather than cattle) densities, the population of waterfleas (rather than grass) can collapse into an overexploited state. The new thing is that, at low fish densities, waterfleas and algal populations oscillate around the equilibrium line in a "predator-prey" cycle. With increasing fish predation, the waterflea population collapses. However, due to the oscillations, this does not happen at the usual point, namely the bend $\left(F_{2}\right)$ in the sigmoidal curve, but already at a much lower fish density, namely at point $O_{1}$. Here, the cycles hit the middle section of the sigmoidal curve that marks the critical border of the attraction valley, and the system inevitably collapses into the alternative state with almost no waterfleas and a dense population of algae. In the cryptic language of dynamical systems theory, this is called a "homoclinic bifurcation." In biological terms, it implies a collapse into another state due to a combination of two different mechanisms: first, the waterflea numbers crash, due largely to depletion of their food, and, subsequently, the population is trapped at this low level by fish predation. The latter is an overexploited state, analogous to that described for overgrazed grasslands. The difference from the classical Noy-Meir model (Fig. 7) is that the population oscillations make the waterfleas more vulnerable to overexploitation by fish. In a sense, the oscillations have the same effect as external perturbations: they increase the probability that the system will shift from one state to another.

Fig. 10. Schematic representation of the predicted effect of fish on the dynamics of zooplankton and algae (from Scheffer et al. 1997).

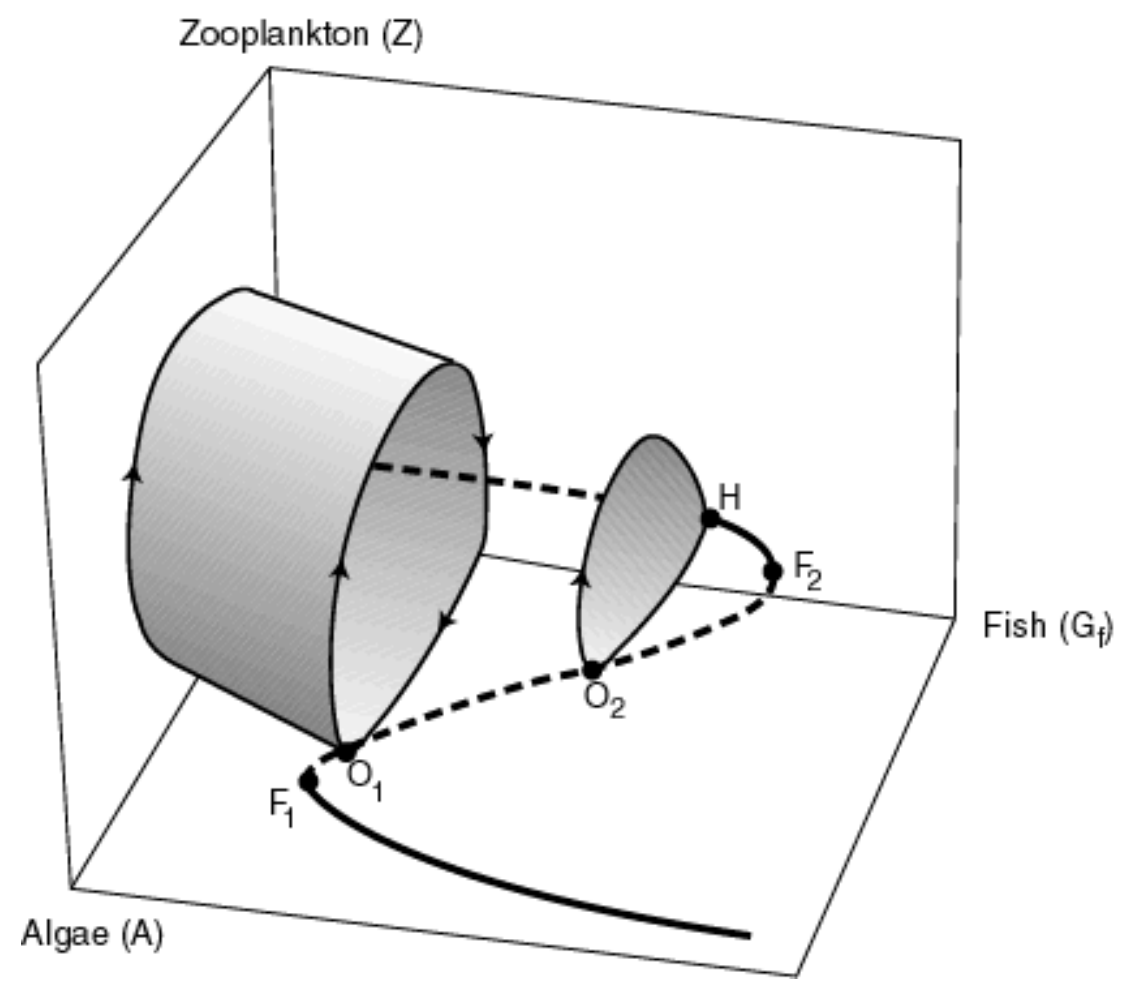

To see how this piece of food chain theory applies to lakes, we must consider the typical pattern of seasonal plankton dynamics. Surely, one of the most distinctive events in the seasonal cycle of lake plankton is the clear-water phase that often occurs at the end of spring. This dip in algal biomass is caused by heavy grazing on algae by waterfleas that peak after the spring algal bloom. The phenomenon can be especially spectacular in eutrophic lakes, where this short clear period contrasts strongly with the turbid situation during the rest of the growing season. This outbreak of waterfleas, with a resulting clear-water phase and the subsequent population collapse, can be seen as a classical predator-prey cycle, waterfleas being the predator and algae the prey. Unlike most predator-prey oscillations, however, the clear-water phase is just a single "cycle" that does not repeat. Usually, after the collapse of the spring peak, waterfleas do not recover for the rest of the year, except for an occasional extra peak in autumn. The traditional explanation for the failure of waterfleas to recover from the spring collapse has been that the algal food in summer is of poor quality due to the increase in inedible colonies of blue-green algae. However, evidence has recently accumulated in favor of an alternative explanation: fish. Most fish species in temperate lakes spawn in spring. When the larvae have used up food reserves in the yolk sac, they become dependent on small planktonic food. At first, only very small food particles are consumed, but in a few 
weeks the animals have grown enough to consume larger food, and waterfleas become one of the preferred foods. As a result, fish predation on waterfleas increases; with the growth of the young fish, their consumptive capacity keeps rising steeply in early summer.

The coincidence of the biomass increase of young-of-the-year fish with the collapse of waterfleas suggests that fish predation may actually be an important cause of this collapse. On the other hand, food shortage is likely to be a major problem for zooplankters during the clear-water phase, when algal biomass can be extremely low. Careful analyses of dynamics of demography and nutritional status of plankton and fish in American and Dutch lakes have revealed that the spring peak of waterfleas collapses due to food shortage, whereas the populations are subsequently kept low by fish predation (Luecke et al. 1990, Boersma et al. 1996). This is exactly the "homoclinic bifurcation" predicted by the model to happen for increasing fish predation (Fig. 10).

Fish predation is not the only thing changing over the year. Light and temperature are probably the most important driving forces behind the seasonal dynamics of ecosystems. A simple way to include seasonal variation in these conditions in an ecological simulation model is to impose a periodically varying "force," such that processes that depend on temperature and light speed up in summer and slow down in winter. When we do this to our simple plankton model and also account for the fish reproduction cycle, a fascinating thing happens: it starts behaving astonishingly like nature (Scheffer et al. 1997). The typical pattern is that an algal bloom occurs in spring, followed by a peak of waterfleas, resulting in a clear-water phase. In summer the algae dominate, but in fall another small peak of waterfleas causes a drop in algal biomass. All population densities stay low throughout the winter until spring sets off a new algal bloom. This whole sequence of events is the classical scenario described for real lakes and, surprisingly, everything generated by the model happens with a timing that closely mimics what we see in real lakes. Also, the patterns are very robust. Moderate changes in the model or in parameter values do not affect the main patterns.

The puzzling question remains: to what extent does the simple two-equation model used actually capture the essence of what drives the system? Clearly, many more mechanisms are involved in seasonal patterns in nature. Waterfleas, for instance, can survive the winter as inert "winter eggs" that hatch massively upon certain environmental triggers. This and many other aspects are not in the model, yet it gives the right results. The art of interpreting model results is the topic of the final section of this essay.

\section{CHAOS IN PLANKTON DYNAMICS}

It is quite surprising that overall seasonal dynamics of the ecosystem are more-or-less predictable if we look at the patterns in total abundance of lumped groups such as fish, zooplankton, and phytoplankton. If we zoom in to the species level, things usually look overwhelmingly erratic. In practice, phytoplankton in a lake may consist of hundreds of algal species, and although the rise and fall of some dominant species are often repeated over years, the peaks and dips in abundance of most populations seem to occur in a highly irregular pattern.

Interestingly, the mere fluctuations in plankton abundance may well explain why there are so many species. In a classical paper entitled "The paradox of the plankton," Hutchinson (1961) drew attention to the fact that the high diversity of phytoplankton is really remarkable, as there seems little room for specialization in this relatively homogeneous environment where everything is competing for a few limiting nutrients and light. Indeed, competition theory suggests that the number of species that can coexist in equilibrium cannot be greater than the number of limiting resources unless additional mechanisms are involved. Hutchinson himself suggested that the plankton community might not be in equilibrium at all, and that this would explain the paradox. However, the question of what actually drives the non-equilibrium dynamics remained. The continuous variation in environmental conditions, due to the seasonal cycle and less predictable factors such as changes in weather and hydraulic conditions, seems an obvious and sufficient explanation (Sommer 1984, Reynolds et al. 1993, Sommer et al. 1993). It is usually thought that, in the absence of any externally imposed disturbance, algal succession should in 1-2 months lead to a stable state in which most species have been outcompeted by one or a few dominants. Indeed, many biologists still feel that there is a kind of underlying "equilibrium of nature" to which ecosystems would settle if, in some miraculous way, the seasons and all variations in their environment could be abandoned. For those believers, the outcome of lab experiments by a team of Dutch plankton ecologists should be puzzling. In the 1970s, these scientists constructed planktonic micro-ecosystems in the laboratory that were kept for years under carefully controlled, constant conditions (Ringelberg and Kersting 1978, Kersting 1985). To their surprise, the populations of competing algae in their compartments did not settle to an equilibrium. Instead, they kept displaying irregular fluctuations. Because the environment was kept constant, this restlessness seemed to come from the interaction of species in the system.

Most likely what they saw was the now well-known phenomenon of "chaos" (Scheffer 1991b). Patterns of fluctuation never repeat exactly, but are the result of purely deterministic processes, despite their erratic look. The first person who pointed out this puzzling phenomenon was the meteorologist Edward Lorenz (Lorenz 1964), who saw it produced by his simple computer model of the mondial weather system. Later, it was generated from many 
different mathematical models, including simple models of planktonic food webs (Doveri et al. 1993, Caswell and Neubert 1998, Rinaldi and Solidoro 1998, Gragnani et al. 1999). An intriguing property of chaotic dynamics is that if one were to "run" two identical systems simultaneously, even the slightest difference between the initial condition of the two would, in time, blow up exponentially to produce completely different dynamics in the long run. Similarly, the effect of small disturbances blows up exponentially with time. This has been called the butterfly effect, as a flapping wing of a butterfly in China could, in the long run, affect the course of the chaotic mondial weather system in such a way as to cause a hurricane to hit Florida. This implies that the behavior of such chaotic systems is fundamentally unpredictable over longer time spans. The inaccuracy of weather predictions more than a few days ahead is an everyday illustration of this principle.

The suggestion that ecosystems, too, might be chaotic, has prompted many attempts to find out if such deterministic chaos is really present in nature (Pool 1989, Hastings et al. 1993, Upadhyay et al. 1998).

Unfortunately, this appears to be extremely difficult. The micro-ecosystem experiments, however, suggest that the mere competition of many algal species can cause chaotic dynamics. Another reason to expect chaos in plankton is the observation from physics that oscillators that are allowed to affect each other can very easily start behaving in a chaotic way. in reality, lake communities are full of interacting oscillators. Here, the "oscillators" are predator-prey couples in the plankton. As explained earlier, waterflea populations tend to oscillate due to periodic overexploitation of their algal food. In practice, there are always many different species of waterfleas and other zooplankters. All of these oscillating populations affect each other through competition, resulting in a set of "interacting oscillators" that seems likely to produce chaotic dynamics, a prediction that is confirmed by several more specific food web models.

If algal competition and zooplankton cycles are indeed the seeds of chaos, what we see in real lakes is the behavior of an intrinsically chaotic system affected by an equally erratically fluctuating environment. It may be argued that, in the end, there is not much difference between intrinsic chaos or the effect of fluctuations in the environment because, for all practical purposes, the result is just noise. Conceptually, however, the implications of chaos are impressive: there is no equilibrium and dynamics are fundamentally unpredictable.

\section{SO, WHAT DO MODELS REALLY TELL US?}

The fact that intriguing and complex patterns in nature can often be explained by simple models is seductive to many scientists. However, others feel almost instinctively repulsed by the minimal model approach. This split is notoriously pronounced among biologists. Nonetheless, most people agree that scientific progress benefits from the combination of models and experiments, so it is worthwhile to analyze the causes of this traditional antagonism. Clearly, models are nothing but simple theories about the cause of observed patterns, and the use of simple hypotheses for explaining patterns in nature has some tricky problems that have been discussed over and over in the history of science.

First of all, theory is tentative by definition and, as Chamberlin (1897) remarked a century ago, we should be alert to "the imminent danger of an unconscious selection and of a magnifying of phenomena that fall into harmony with the theory and support it and an unconscious neglect of phenomena that fail of coincidence. "Keeping an open eye for alternative explanations is important in all science, but it is especially essential in biology. In fact, even the classic ideas about hypothesis testing are of rather limited use in sciences that deal with complex systems such as ecology, climatology, and economy. A small excursion to the history of the discussion on this topic may clarify this.

The classical way of doing proper science is the hypothetico-deductive approach. Its main ideas were advocated as early as 1620 by Francis Bacon in his Novum Organum, and were elaborated later by the influential science philosopher Karl Popper. In the early 1960s, John R. Platt (1964) argued once more that this systematic method of scientific thinking, which he calls "strong inference," clearly produces much more rapid progress than anything else, and hence should be closely adhered to. The steps of strong inference as formulated by Platt are:

1. Devising alternative hypotheses;

2. Devising a crucial experiment (or several of them) with alternative possible outcomes, each of which will, as nearly as possible, exclude one or more of the hypotheses;

3. Carrying out the experiment so as to get a clean result;

4. Recycling the procedure, making subhypotheses or sequential hypotheses to refine the possibilities that remain; and so on.

According to Platt, the superiority of this approach is overwhelming. As he phrases it: "The difference between the average scientist's informal methods and the methods of the strong-inference users is somewhat like the difference between a gasoline engine that fires occasionally and one that fires in steady sequence. If our motorboat engines were as erratic as our deliberate intellectual efforts, most of us would not get home for supper." Platt's compelling 
plea inspired many ecologists. It was felt that unsystematic working methods could indeed be the reason that ecology was not proceeding at the pace of sciences like molecular biology and high-energy physics put forward as examples by Platt. It was argued that hard-to-crack problems, such as understanding the effect of competition on natural communities, could only be solved by following the path of null-hypothesis formulation and testing (Connor and Simberloff 1979, Strong 1983).

In the 1980s, however, some well-known ecologists started pointing out that there are some fundamental reasons why rigid, strong inference is of very limited use in their branch of science (Quinn and Dunham 1983, Roughgarden 1983). The most basic argument is that strong inference assumes that the competing hypotheses to explain observed phenomena are general and mutually exclusive, whereas in ecosystems, several independent mechanisms often contribute to an observed phenomenon that could, in theory, also be explained by each mechanism alone. One of the mechanisms will often dominate, but dominance will differ from case to case and may even shift in time. In practice, this means that "clean," controlled microcosm experiments, although easy to publish in scientific journals, tell us little about the suite of mechanisms that drive real ecosystem dynamics (Carpenter 1996).

With respect to the interpretation of simple models, the problem of multiple causality implies that some modesty is appropriate (Scheffer and Beets 1994). Even if the model is based on reasonable assumptions and its behavior mimics patterns in the real system very well, it might be that these patterns are caused by something else in reality. The fact that the modeled mechanisms can be shown to operate in the field is not a sufficient basis for concluding that they offer the appropriate explanation in that specific case: the modeled mechanism may well be acting in concert with other, possibly more important, mechanisms.

Failure to recognize this status of models has contributed significantly to the antagonism between theoreticians and naturalists. Theoreticians tend not to pay much attention to the fact that their natural objects of study usually correspond to only one of many hypotheses for a phenomenon. Rather, they feel that their job is done when one of these hypotheses is satisfactorily modeled. To naturalists, this attitude may give the impression that the theoretician pretends to offer the one and only explanation for the phenomenon in nature. Because it is always obvious that many important factors are left out of the model, this claim may seem so ridiculous that it is not even worth a response. The situation is easily polarized if theoreticians adhere to the ideal of simplicity and consider their explanation better for the mere reason that it is simpler, i.e., that it requires less biological detail. Probably this will be exactly the reason why many naturalists dislike it, because they strive rather to perceive the richness of biological detail.

Only if theoreticians present results of models in an accessible way and with appropriate modesty will their work inspire rather than irritate. The nicest results of model analyses are those that are, at first sight, counterintuitive. These indicate mechanisms that, because of their counterintuitiveness, would probably never have occurred to us if we had used only common sense. A somewhat counterintuitive explanation obtained from a model may feel less safe and convincing than a common-sense explanation, but the reliability of human feeling in these matters is at least questionable. After all, common sense is also the thing that tells us that the world is flat. In addition to suggesting alternative explanations for phenomena observed in nature, mathematical models can effectively enhance our insight into mechanisms that are difficult to grasp intuitively. Playing around with such models gives a feeling for the effects of the intertwined feedback systems often encountered in ecology.

An important advantage of the high abstraction level of theoretical models is that their results are rather independent of details that may differ from case to case in the real world. For instance, aquatic plants affect the turbidity of water through many mechanisms, several of which are still poorly understood. However, despite controversy about many of the involved mechanisms, there is a broad consensus on the idea that vegetation enhances water clarity. As shown, this empirical relationship is sufficient to construct a model that explains the possibility that lakes may flip between alternative equilibrium states. By skipping the level of describing the manifold of controversial mechanisms by which plants enhance clarity, and picking up the phenomenon at a higher abstraction level where consensus on an empirical relationship can be found, the theoretical model is not only kept simple and understandable, but also general. In fact, if we were to replace the labels on the axes with abstract symbols, graphs such as the ones in this essay would be general enough to apply to a multitude of very different problems.

\section{THEORY AS A BRIDGE BETWEEN DISCIPLINES}

The generality of this type of theory makes it a potentially ideal bridge of communication between scientific disciplines that are usually not in touch. A desert ecologist will rarely read the scientific literature on lakes, and it is even more unlikely that a lake ecologist would dig into the history of despotism in ancient China or the functioning of pancreatic cells. Nonetheless, such seemingly disparate study objects can have surprisingly strong similarities when viewed on the abstract level of dynamical systems theory (Scheffer and Jeppesen 1998, Scheffer et al. 1999). Numerous other examples exist of comparable models describing similar patterns in widely different ecological and 
social systems, ranging from boreal forests to commercial companies and love-couples (Ludwig et al. 1978, Holling 1986, Gunderson et al. 1995, Holling and Meffe 1996, Rinaldi 1998). This convergence of models may merely reflect a commonality in human thinking about complex systems. However, I believe that the "other world" of catastrophe folds, homoclinic bifurcations, and strange attractors does indeed mirror the essential governing structures of a surprisingly heterogeneous range of real systems.

For instance, the alternative stable states in flipping lakes arise because plants are able to improve their own growing conditions by clearing the water. Positive effects of plants on plant growth are also known to be important under arid conditions in which heat and drought prevent the colonization of unprotected open areas. In such situations, the establishment of new plants is often restricted to the shade under the canopy of other plants, the so-called nurse plants. The "nurses" can ameliorate thermal and water stress, improve soil properties, and often also reduce the probabilities of herbivory and mechanical damage to the sensitive seedlings (Holmgren et al. 1997). The net effect is quite similar to that described for flipping lakes: when plants are absent, colonization is impossible, but once vegetation is present, it can remain stable because it improves the conditions for plant growth, in this case by offering protective cover that allows plants to pass the crucial juvenile stage (Rietkerk and Van de Koppel 1997, Van de Koppel and Prins 1998). Thus, on a higher abstraction level, the irreversible character of desertification is quite comparable to the problems encountered in the restoration of lakes.

"Homoclinic transitions," in which an oscillation in the system triggers a collapse to an alternative state, are another example of a phenomenon probably widespread in nature. I described it in this essay for waterflea populations that collapse due to overexploitation of their food and are unable to recover due to fish predation. Current ideas about the mechanism that causes the famous cycles in populations of snowshoe hares and lynx are closely related (Keith 1990). The decline in the hare population that sets off the cycle is initiated by a food limitation of hares that have overgrazed the vegetation. When the hare population has collapsed to low numbers, the impact of the predator populations, whose numbers stay roughly constant, becomes increasingly important, keeping the hare population low for an extended period. Homoclinic transitions are also described for the activity of pancreatic cells and the alternation between despotism and anarchy in ancient China.

Most likely, there are countless other systems that are studied by completely different scientific disciplines but that share the same governing mechanisms in abstract terms. Different branches of science are notoriously isolated, but it is well known that the rare occasions of contact, for instance, when a scientist switches to a different discipline, can generate great progress. Applying insights gained from one system to another is often the key to such success. One would expect that dynamical systems theory could be the perfect vehicle for transmitting insights in complex systems behavior between scientific disciplines, but in reality, the role of theory as such has been quite minimal so far. In fact, many theoreticians seem to live quite happily in that "other world out there" in which things are beautifully clear and controllable. This attitude is quite understandable. Translation of the secret language of theoreticians to the jargon of various branches of science and vice versa is a quite cumbersome process. Also, patterns in the real world are typically the result of a messy mix of mechanisms, and it somehow feels better to keep your hands clean and work in the perfect world of models than to muddle with data sets that may always be interpreted in many ways. The reward, however, is potentially huge. Bridging the gap between theory and practice could help to bridge the gaps between the multitude of scientific disciplines trying to unravel the forces that drive the behavior of all kinds of complex systems. Such a cross-fertilization would surely boost our understanding of many problems, an understanding that is crucial if we want to carve the future in a way that makes this world a better place to live for us and many other species.

\section{RESPONSES TO THIS ARTICLE}

Responses to this article are invited. If accepted for publication, your response will be hyperlinked to the article. To submit a comment, follow this link. To read comments already accepted, follow this link.

\section{Acknowledgments:}

I would like to thank C. S. Holling for stimulating me to write this essay, Steve Carpenter for helpful comments and insights, and Sergio Rinaldi, Rob de Boer, Donald DeAngelis, and my collegues at RIZA and Wageningen Agricultural University for many exiting discussions about the topics touched on in this essay.

\section{LITERATURE CITED}

Barko, J. W., and W. F. James. 1998. Effects of submerged aquatic macrophytes on nutrient dynamics, sedimentation, and resuspension. Pages 197-214 in E. Jeppesen, M. Sondergaard, M. Sondergaard, and K. Kristoffersen, editors. Structuring role of submerged macrophytes in lakes. Volume 131. Springer-Verlag, New York, New York, USA. 
Boersma, M., O. F. Van Tongeren, and W. M. Mooij. 1996. Seasonal patterns in the mortality of Daphnia species in a shallow lake. Canadian Journal of Fisheries and Aquatic Sciences 53:18-28.

Camerano, L. 1880. Dell'equilibrio dei viventi merce la reciproca distruzione. Accademia delle Scienze di Torino 15: 393-414. (translated in the cited source by C. M. Jacobi and J. E.Cohen (1994): On the equilibrium of living beings by means of reciprocal destruction). Pages 360-380 in S. A. Levin, editor. Frontiers in mathematical biology. Springer-Verlag, Berlin, Germany.

Carpenter, S. R. 1996. Microcosm experiments have limited relevance for community and ecosystem ecology. Ecology 77:677-680.

Carpenter, S. R., J. F. Kitchell, and J. R. Hodgson. 1985. Cascading trophic interactions and lake productivity. BioScience 35:634-639.

Caswell, H., and M. G. Neubert. 1998. Chaos and closure terms in plankton food chain models. Journal of Plankton Research 20:1837-1845.

Chamberlin, T. C. 1897 . The method of multiple working hypotheses. Journal of Geology 5:837-848.

Connor, E. F., and D. Simberloff. 1979. The assembly of species communities: chance or competition? Ecology 60: $1132-1140$.

Doveri, F., M. Scheffer, S. Rinaldi, S. Muratori, and Y. A. Kuznetsov. 1993. Seasonality and chaos in a plankton-fish model. Theoretical Population Biology 43:159-183.

Gragnani, A., M. Scheffer, and S. Rinaldi. 1999. Top-down control of cyanobacteria: A theoretical analysis. American Naturalist 153:59-72.

Gross, E. M. 1999. Allelopathy in benthic and littoral areas: case studies on allochemicals from benthic cyanobacteria and submersed macrophytes. Pages 179-199 in Inderjit, C. L. Foy, and K. M. Dakshini, editors. Principles and practices in plant ecology: allolochemical interactions. CRC Press, Begell House.

Gross, E. M., H. Meyer, and G. Schilling. 1996. Release and ecological impact of algicidal hydrolysable polyphenols in Myriophyllum spicatum. Phytochemistry 41:133-138.

Gulati, R. D., E. H. R. R. Lammens, M. L. Meijer, and E. Van Donk. 1990. Biomanipulation tool for water management. Proceedings of an International Conference held in Amsterdam, The Netherlands, 8-11 August 1989. 1: Kluwer Academic Publishers, Dordrecht, The Netherlands.

Gunderson, L. H., C. S. Holling, and S. S. Light. 1995. Barriers and bridges to the renewal of ecosystems and institutions. Columbia University Press, New York, New York, USA.

Hairston, N., F. E. Smith, and D. Slobodkin. 1960. Community structure, population control, and competition. American Naturalist 94:421-425.

Hastings, A., C. L. Hom, S. Ellner, and P. Turchin. 1993. Chaos in ecology - Is mother nature a strange attractor? Annual Review of Ecology and Systematics 24:1-33.

Holling, C. S. 1986. Resilience and ecosystems; local surprise and global change. Pages 292-317 in W. C. Clark and R. E. Munn, editors. Sustainable development of the biosphere. Cambridge University Press, New York, New York, USA.

Holling, C. S., and G. K. Meffe. 1996. Command and control and the pathology of natural resource management. Conservation Biology 10:328-337.

Holmgren, M., M. Scheffer, and M. A. Huston. 1997. The interplay of facilitation and competition in plant communities. Ecology 78:1966-1975.

Hutchinson, G. E. 1961. The paradox of the plankton. American Naturalist 95:137-145.

James, W. F., and J. W. Barko. 1994. Macrophyte influences on sediment resuspension and export in a shallow impoundment. Lake Reservoir Management 10:95-102.

Jeppesen, E., J. P. Jensen, P. Kristensen, M. Sondergaard, E. Mortensen, O. Sortkjaer, and K. Olrik. 1990. Fish manipulation as a lake restoration tool in shallow, eutrophic, temperate lakes 2: Threshold levels, long-term stability and conclusions. Hydrobiologia 200/201:219-228.

Jeppesen, E., T. L. Lauridsen, T. Kairesalo, and M. R. Perrow. 1998. Impact of submerged macrophytes on 
fish-zooplankton interactions in lakes. Pages 91-114 in E. Jeppesen, M. Sondergaard, M. Sondergaard, and K. Kristoffersen, editors. Structuring role of submerged macrophytes in lakes. Volume 131. Springer-Verlag, New York, New York, USA.

Keith, L. B. 1990. Dynamics of snowshoe hare populations. Current Mammalogy 2:119-195.

Kersting, K. 1985. Properties of an aquatic micro-ecosystem V. Ten years of observations of the prototype. Verhandlungen Internationale Vereinigung Theoretisch Angewandte Limnologie 22:3040-3045.

Kogan, S., and G. A. Chinnova. 1972. Relations between Ceratophyllum demersum and some blue-green algae. Hydrobiological Journal (English translation from Gidrobiolicheskii Zhurnal) 8:14-19.

Kufel, L., and T. Ozimek. 1994. Can Chara control phosphorus cycling in Lake Luknajno (Poland)? Hydrobiologia 276:277-283.

Lauridsen, T. L., E. Jeppesen, M. Sondergaard, and D. M. Lodge. 1998. Horizontal migration of zooplankton: Predator-mediated use of macrophyte habitat. Pages 233-239 in E. Jeppesen, M. Sondergaard, M. Sondergaard, and K. Kristoffersen, editors. Structuring role of submerged macrophytes in lakes. Volume 131. Springer-Verlag, New York, New York, USA.

Lauridsen, T. L., and D. M. Lodge. 1996. Avoidance by Daphnia magna of fish and macrophytes: chemical cues and predator-mediated use of macrophyte habitat. Limnology and Oceanography 41: 794-798.

Lorenz, E. N. 1964. The problem of deducing the climate from the governing equations. Tellus 16:1-11.

Ludwig, D., D. D. Jones, and C. S. Holling. 1978. Qualitative analysis of insect outbreak systems: the spruce budworm and forest. Journal of Animal Ecology 47:315-332.

Luecke, C., M. J. Vanni, J. J. Magnuson, and J. F. Kitchell. 1990. Seasonal regulation of Daphnia populations by planktivorous fish: implications for the spring clear-water phase. Limnology and Oceanography 35:1718-1733.

McCauley, E., and W. W. Murdoch. 1987. Cyclic and stable populations: Plankton as paradigm. American Naturalist 129:97-121.

McQueen, D. J., and J. R. Post. 1988. Cascading trophic interactions uncoupling at the zooplanktonphytoplankton link. Hydrobiologia 159:277-296.

Meijer, M. L., E. Jeppesen, E. Van Donk, and B. Moss. 1994. Long-term responses to fish-stock reduction in small shallow lakes: Interpretation of five-year results of four biomanipulation cases in the Netherlands and Denmark. Hydrobiologia 276:457-466.

Mills, E. L., J. L. Forney, and K. J. Wagner. 1987. Fish predation and its cascading effect on the Oneida Lake food chain. Paages 118-131 in W. C. Kerfoot and A. Sih, editors. Predation: Direct and indirect impacts on aquatic communities. University Press of New England.

Moss, B. 1987. The art of lake restoration. New Scientist :41-43. . 1988. Ecology of fresh waters. Second edition. Man and Medium 2. Blackwell Scientific, Oxford, UK.

Noy-Meir, I. 1975. Stability of grazing systems an application of predator-prey graphs. Journal of Ecology 63:459-482.

Platt, J. R. 1964. Strong inference. Certain systematic methods of scientific thinking may produce much more rapid progress than others. 146:347-353.

Pool, R. 1989. Is it chaos, or is it just noise? Science 243:25-28.

Quinn, J. F., and A. E. Dunham. 1983. On hypothesis testing in ecology and evolution. 122:602-617.

Reynolds, C. S., J. Padisak, and U. Sommer. 1993. Intermediate disturbance in the ecology of phytoplankton and the maintenance of species diversity a synthesis. Hydrobiologia 249:183-188.

Rietkerk, M., and J. Van de Koppel. 1997. Alternate stable states and threshold effects in semi-arid grazing systems. 79:69-76.

Rinaldi, S. 1998a. Love dynamics: The case of linear couples. Applied Mathematics and Computation 95:181-192.

Rinaldi, S., and C. Solidoro. 1998b. Chaos and peak-to-peak dynamics in a plankton-fish model. Theoretical Population Biology 54:62-77. 
Ringelberg, J., and K. Kersting. 1978. Properties of an aquatic micro ecosystem I. General introduction to the prototypes. Archiv für Hydrobiologie 83:47-68.

Roughgarden, J. 1983. Competition and theory in community ecology. American Naturalist 122:583-601.

Scheffer, M. 1990. Multiplicity of stable states in freshwater systems. Hydrobiologia 200/201:475-486.

. 1991a. Fish and nutrients interplay determines algal biomass: A minimal model. Oikos 62:271-282.

. 1991b. Should we expect strange attractors behind plankton dynamics: And if so, should we bother?

Journal of Plankton Research 13:1291-1306.

. 1997. Ecology of shallow lakes. Kluwer Academic Publishers, Dordrecht, NL.

Scheffer, M., and J. Beets. 1994. Ecological models and the pitfalls of causality. Hydrobiologia 276:115-124.

Scheffer, M., S. H. Hosper, M. L. Meijer, and B. Moss. 1993. Alternative equilibria in shallow lakes. Trends in Ecology and Evolution 8:275-279.

Scheffer, M., and E. Jeppesen. 1998. Alternative stable states. Pages 397-406 in E. Jeppesen, M. Sondergaard, M. Sondergaard, and K. Kristoffersen, editors. Structuring role of submerged macrophytes in lakes. Volume 131. Springer-Verlag, New York, New York, USA.

Scheffer, M., S. Rinaldi, and Y. A. Kuznetsov. 1999. The effect of fish on plankton dynamics: a theoretical analysis. Canadian Journal of Fisheries and Aquatic Sciences, in press.

Scheffer, M., S. Rinaldi, Y. A. Kuznetsov, and E. H. Van Nes. 1997. Seasonal dynamics of Daphnia and algae explained as a periodically forced predator-prey system. Oikos 80:519-532.

Sommer, U. 1984. The paradox of the plankton: Fluctuations of phosphorus availability maintain diversity of phytoplankton in flow-through cultures. Limnology and Oceanography 29:633-636.

Sommer, U., J. Padisak, C. S. Reynolds, and P. Juhasz-Nagy. 1993. Hutchinson's heritage the diversitydisturbance relationship in phytoplankton. Hydrobiologia 249:1-7.

Strong, D. R., Jr. 1983. Natural variability and the manifold mechanisms of ecological communities. American Naturalist 122:636-660.

Timms, R. M., and B. Moss. 1984. Prevention of growth of potentially dense phytoplankton populations by zooplankton grazing in the presence of zooplanktivorous fish in a shallow wetland ecosystem. Limnology and Oceanography 29:472-486.

Upadhyay, R. K., S. R. K. Iyengar, and V. Rai. 1998. Chaos: An ecological reality? International Journal of Bifurcation and Chaos 8:1325-1333.

Van de Koppel, J., and H. H. T. Prins. 1998. The importance of herbivore interactions for the dynamics of African savanna woodlands: an hypothesis. Journal of Tropical Ecology 14 (5):565-576.

Van Donk, E., R. D. Gulati, A. Iedema, and J. T. Meulemans. 1993. Macrophyte-related shifts in the nitrogen and phosphorus contents of the different trophic levels in a biomanipulated shallow lake. Hydrobiologia 251:19-26.

\section{Address of Correspondent:}

Marten Scheffer

Aquatic Ecology and Water Quality Management Group

Department of Environmental Sciences

Wageningen Agricultural University

P.O. Box 8080, NL-6700 DD

Wageningen, The Netherlands

Phone: (31) 317484039

Fax: (31) 317484411

Marten.Scheffer@AQEC.WKAO.WAU.NL

*The copyright to this article passed from the Ecological Society of America to the Resilience Alliance on 1 January 2000. 
Home | Archives | About | Login | Submissions | Notify | Contact | Search 